\title{
Immobilization of 2-Deoxy-D-ribose-5-phosphate Aldolase in Polymeric Thin Films via the Langmuir-Schaefer Technique
}

\author{
Stefan Reinicke, ${ }^{* \dagger} \oplus$ Huw C. Rees, ${ }^{\dagger}$ Pieter Espeel, ${ }^{\S}$ Nane Vanparijs, ${ }^{\|}$Carolin Bisterfeld, ${ }^{\perp}$ Markus Dick, ${ }^{\perp}$ \\ Ruben R. Rosencrantz, ${ }^{\dagger, \nabla}$ Gerald Brezesinski, ${ }^{\#}$ Bruno G. de Geest, ${ }^{\prime \prime}$ Filip E. Du Prez, ${ }^{\text {() }}$ \\ Jörg Pietruszka, ${ }^{\perp, \triangle} \triangle_{\odot}$ and Alexander Böker ${ }^{\dagger, \nabla} \nabla_{\odot}$ \\ ${ }^{\dagger}$ Department of Functional Protein Systems and Biotechnology, Fraunhofer Institute of Applied Polymer Research (IAP), \\ Geiselbergstraße 69, 14476, Potsdam-Golm, Germany \\ ${ }^{\ddagger}$ Department of Chemistry, University of Chicago, Chicago, Illinois 60637, United States \\ ${ }^{\S}$ Department of Organic and Macromolecular Chemistry, Polymer Chemistry Research Group, Ghent University, Krijgslaan 281 \\ S4-bis, 9000 Ghent, Belgium \\ "Department of Pharmaceutics, Ghent University, Ottergemsesteenweg 460, 9000 Ghent, Belgium \\ ${ }^{\perp}$ Institut of Bioorganic Chemistry, Heinrich Heine University of Düsseldorf at Forschungszentrum Jülich, Stetternicher Forst, \\ D-52426 Jülich, Germany \\ ${ }^{\#}$ Max Planck Institute of Colloids and Interfaces, Science Park Potsdam-Golm, Am Mühlenberg 1, 14476 Potsdam, Germany \\ $\triangle$ IBG-1: Biotechnology, Forschungszentrum Jülich GmbH, 52425 Jülich, Germany \\ $\nabla_{\text {Polymer Materials and Polymer Technologies, University of Potsdam, 14476, Potsdam-Golm, Germany }}$
}

Supporting Information

ABSTRACT: A synthetic protocol for the fabrication of ultrathin polymeric films containing the enzyme 2-deoxy-Dribose-5-phosphate aldolase from Escherichia coli $\left(\mathrm{DERA}_{\mathrm{EC}}\right)$ is presented. Ultrathin enzymatically active films are useful for applications in which only small quantities of active material are needed and at the same time quick response and contact times without diffusion limitation are wanted. We show how DERA as an exemplary enzyme can be immobilized in a thin polymer layer at the air-water interface and transferred to a suitable support by the Langmuir-Schaefer technique under full conservation of enzymatic activity. The polymer in use is a poly $(N$-isopropylacrylamide-co- $N$-2-thiolactone acrylamide) (P(NIPAAm-co-TlaAm)) statistical copolymer in which the thiolactone units serve a multitude of purposes including hydrophobization of the polymer, covalent binding of the enzyme and the support and finally cross-linking of the polymer matrix. The application of this type of polymer keeps the whole approach simple as additional cocomponents such as cross-linkers are avoided.

KEYWORDS: Langmuir-Schaefer, enzyme immobilization, 2-deoxy-D-ribose-5-phosphate aldolase, polymeric thin film, poly(N-isopropylacrylamide), thiolactone

\section{INTRODUCTION}

For the industrial application of enzymes, immobilization of the biocatalyst can be of great benefit. Not only does it typically enhance enzyme stability, ${ }^{1-4}$ it also avoids the laborious purification steps, ${ }^{5}$ enables a reuse of the enzyme and eventually offers the opportunity for alternative process designs like switching from discontinuous to continuous operation mode. $^{6-9}$ A specific case of enzyme immobilization is the formation of ultrathin enzyme containing films that in turn are deposited on different types of support material, a strategy that is already well established. ${ }^{10-14}$ The small thickness of such layers is relevant in cases where only small quantities of active material are needed and at the same time quick response and contact times without diffusion limitation are wanted. Consequently, such systems are mostly found in sensor applications; $^{13-16}$ however, they can also play a role in biocatalysis. $^{9-11}$ A common approach toward such films is the electropolymerization of suitable monomers on electrode surfaces in the presence of an enzyme, a strategy that has been extensively used for the immobilization of redox active enzymes. Bartlett et al., for instance, immobilized glucose oxidase $(\mathrm{GOx})^{17,18}$ and horseradish peroxidase ${ }^{19}$ on electrode

Received: October 25, 2016

Accepted: February 10, 2017

Published: February 10, 2017 
surfaces to couple the redox reaction catalyzed by the enzyme with a signal transducing concept for sensing purposes. While this approach appeared to be very effective in terms of maintenance of enzymatic activity and control of film thickness, it is limited to electropolymerizable monomers and to enzymes that exhibit a certain surface charge at the chosen immobilization conditions. The film thicknesses, at least in the case were it was reported, where settled in the range between several tens of nanometers and a few micrometers. ${ }^{18}$

Another opportunity to generate ultrathin enzyme films, which is in principle applicable to any water-soluble protein, is to adsorb the enzyme to an air-water interface from where it is transferred to a suitable support. In that way, even films as thin as a molecular monolayer may be generated. However, direct adsorption to the interface can be problematic, since most water-soluble proteins undergo conformational changes in that case. $^{20-23}$ Besides, even if activity maintenance can be achieved, which is possible in certain cases by an optimization of the adsorption procedure, ${ }^{22}$ an additional cross-linking step using compounds like glutaraldehyde is needed in order to obtain a physically stable film in the end. However, such low molecular weight cross-linking agents are not always applicable, as the cross-linking, just as the direct adsorption of the enzyme to the interface, may disturb the structure of the latter in a way that deactivation occurs. As an alternative, the enzyme can be adsorbed to and so accommodated within a polymeric film that has been formed at the air-water interface before. This film formation can be easily accomplished by the Langmuir technique. Next to the stabilizing effect, it is envisioned that the direct accommodation within a preformed film further suppresses conformational changes of the enzyme during its adsorption.

When applying such an approach, the polymer film in use must fulfill a certain set of requirements. The film should not only be able to accommodate the enzyme, but also to bind it firmly, ideally in a covalent manner, while being susceptible to a subsequent cross-linking for an enhanced mechanical stability. When using the Langmuir technique for the film formation, the polymer in use should also be rather hydrophobic to form a stable film at the interface. At the same time, however, it should leave the opportunity to get hydrophilized after transfer of the film to provide swellability of the enzyme accommodating matrix in water later during operation.

In this contribution, we utilize a water insoluble poly $(\mathrm{N}$ isopropylacrylamide-co- $\mathrm{N}$-2-thiolactone acrylamide) (P(NIPAAm-co-TlaAm)) statistical copolymer to create an enzyme containing polymeric thin film at the air-liquid interface that is transferable to a solid support (Scheme 1). The thiolactone units of the copolymer ${ }^{24}$ render the film capable of fulfilling all the requirements described above without the need for using additional cocomponents, including initial hydrophobization of the polymer, covalent binding of the enzyme and to the support and finally hydrophilization and cross-linking of the generated film.

As an exemplary enzyme for our immobilization strategy we chose 2-deoxy-D-ribose-5-phosphate aldolase (DERA), an enzyme that is involved in the nucleotide catabolism. ${ }^{25}$ DERA catalyzes a domino aldol reaction, adding two acetaldehydes as donor molecules to a broad range of acceptor aldehydes. As both reaction steps are highly stereoselective, DERA can be utilized for the synthesis of chiral building blocks. One particular example is the use of DERA in an economically
Scheme 1. Formation of DERA-Containing Polymeric Thin Films by the Langmuir-Schaefer Technique Applying a Water Insoluble p(NIPAAm-co-TlaAm) Statistical Copolymer with $31 \mathrm{~mol} \%$ TlaAm

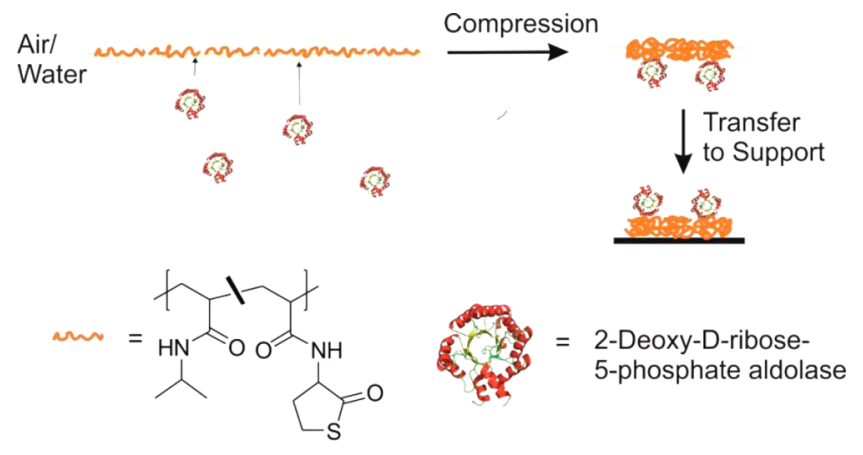

viable process for the synthesis of $\beta, \delta$-dihydroxyaldehyde containing motifs for pharmaceuticals in a fed-batch process. ${ }^{26}$

In case of DERA, the avoidance of a low molecular weight lysine reactive cross-linker like glutaraldehyde is justified by the fact that a lysine residue plays a crucial role in the DERAcatalyzed aldol reaction, which must therefore remain structurally unharmed. ${ }^{27,28}$ Consequently, it appears reasonable to apply an alternative immobilization procedure, such as the one proposed above.

Attempts to immobilize DERA have been reported already; ${ }^{29-32}$ however, all being focused on dispersible (nano)materials as support material and thus not putting any focus on the formation of enzymatically active thin films. Besides, activity maintenance after immobilization was poor ${ }^{30,31}$ or not even reported. ${ }^{32}$

\section{EXPERIMENTAL SECTION}

Materials. Hydrogenperoxide solution (Roth, Rotipuran, 30\%), aminopropyltriethoxysilane (APTES) (Aldrich, 99\%), absolute ethanol (ChemSolute, >99.5\%), dimethyl sulfoxide (DMSO) (Roth, Rotidry, $>99.8 \%,<100 \mathrm{ppm}$ of $\mathrm{H}_{2} \mathrm{O}$ ), $\mathrm{CHCl}_{3}$ (Th.Geyer, >99.5\%), $\mathrm{CDCl}_{3}$ (Roth, 99.8\% D), bovine serum albumin (BSA) (Aldrich, >98\%, lyophilized powder, heat shock fraction), triethanolamine (Aldrich, BioUltra, $>99.5 \%$ ), and Atto-665 maleimide (Atto-Tec), were used as received. The synthetic procedure for the 4-methylumbelliferonecoupled D-xylose substrate is described elsewhere. ${ }^{33}$ The polymer poly $(\mathrm{N}$-isopropylacrylamide-co- $\mathrm{N}$-2-thiolactone acrylamide) (p(NIPAAm-co-TlaAm)) was synthesized via RAFT according to a procedure described in a previous publication. ${ }^{34}$ NMR and SEC analysis revealed a TlaAm content of $31 \mathrm{~mol} \%$ and a relative molecular weight of $12.4 \mathrm{~kg} / \mathrm{mol}$ with a dispersity of 1.34 (DMF-SEC, PS standards). Silicon wafers (p-type, $625 \mu$ m thickness, front side polished) were purchased from CrysTec, glass slides (cut edges) from VWR and microtiter plates (Cellstar, 24 and 96 wells, sterile) from Greiner Bio-One.

Buffers. The $\mathrm{pH}$ of all buffers used was controlled and adjusted using a Mettler Toledo Seven Compact $\mathrm{pH}$-meter that is calibrated with $\mathrm{pH} \mathrm{4,} \mathrm{7,} \mathrm{and} 9$ calibration standards (Mettler Toledo). If not otherwise stated, the term phosphate buffer refers to $20 \mathrm{mM}$ of potassium phosphate in Milli-Q with a $\mathrm{pH}$ adjusted to 7.0.

Production of 2-Deoxy-D-ribose-5-phosphate Aldolase from Escherichia coli $\left(D E R A_{E C}\right)$. For preparation of DERA the protein was expressed in E. coli and purified by NiNTA and PD10 columns according to Dick et al. $^{35}$ Before lyophilization the protein was dissolved in $\mathrm{KP}_{\mathrm{i}}$-buffer at $20 \mathrm{mM}$ and $\mathrm{pH} 7$ and set to a concentration of $\sim 5 \mathrm{mg} / \mathrm{mL}$.

Surface Functionalization of Silicon Wafers and Glass Slides. Si-wafers or glass slides were first cleaned in an ultrasonication bath using first soap solution and then two times Milli-Q water. After blow 
drying, they were treated with oxygen plasma ( $5 \mathrm{~min}, 0.2 \mathrm{mbar}, 100 \mathrm{~W}$, $100 \% \mathrm{O}_{2}$ ) using a PlasmaFlecto 10 Plasma Oven (Plasma Technology) equipped with an oxygen concentrator (525 Series, DeVilbiss). After plasma treatment, the wafers were immediately transferred to absolute ethanol containing 2 wt \% APTES where they were stored for $2 \mathrm{~h}$. Finally, the wafers/slides were washed 3 times with absolute ethanol and dried for $1 \mathrm{~h}$ at $100{ }^{\circ} \mathrm{C}$ in a drying oven. The final wafers/slides were stored in ethanol. The presence of nitrogen on the wafer surface was confirmed by XPS.

Fluorescent Labeling of DERA. $3.1 \mathrm{mg}$ of the lyophilized DERA powder (containing $1.6 \mathrm{mg}$ of the enzyme) were dissolved in $1.6 \mathrm{~mL}$ of PBS buffer. Seven microliters of a solution of Atto- 665 maleimide in dry DMSO $(10 \mathrm{mg} / \mathrm{mL})$ were added and the reaction mixture was left for $3 \mathrm{~h}$ being protected from light. After that, the labeled enzyme was purified by running the reaction mixture over a gel filtration column (Ø $2 \mathrm{~cm}$, length $30 \mathrm{~cm}$ ) packed with Sephadex G-25 using a Knauer Smartline system equipped with a $\$ 1050$ pump, a S5050 manager unit and a $2550 \mathrm{UV}$ detector $(210$ and $280 \mathrm{~nm}$ ). At a flow rate of $5 \mathrm{~mL} /$ min 4 increments of $500 \mu \mathrm{L}$ could be passed through the column before the unbound dye was eluted.

Film Formation and Transfer via Langmuir-Schaefer and Post-treatment. Film formation and transfer were performed on a KSV Nima minitrough system equipped with two symmetrically movable barriers and a trough with $273 \mathrm{~cm}^{2}$ surface area and a volume of $280 \mathrm{~mL}$. Barrier movement was controlled by a servo controlled DC motor and surface pressure was recorded using a platinum Wilhelmy plate attached to a microelectronic feedback system (dynamic range $=$ $0-250 \mathrm{mN} / \mathrm{m}$, resolution $4 \mu \mathrm{N} / \mathrm{m})$. In a typical experiment, the polymer was spread from a $1 \mathrm{mg} / \mathrm{mL}$ solution in $\mathrm{CHCl}_{3}$ onto a phosphate buffer subphase until the desired surface pressure was reached. After leaving the system for $25 \mathrm{~min}$ to ensure complete solvent evaporation, the isotherm was recorded or $0.9 \mathrm{~mL}$ of a stock solution of DERA $(0.6 \mathrm{mg} / \mathrm{mL})$ in phosphate buffer was injected into the subphase. After another waiting period of $90 \mathrm{~min}$, the film was compressed with a barrier speed of $15 \mathrm{~mm} / \mathrm{min}$. After full compression, the film was allowed to relax for $5 \mathrm{~min}$ and a $1 \times 1$ $\mathrm{cm}^{2}$ amino-functionalized $\mathrm{Si}$-wafer or glass slide was dipped horizontally onto the surface to transfer the film. The transfer conditions included a surface pressure of $32 \mathrm{mN} / \mathrm{m}$ and an apparent mma of $350.6 \AA^{2} /$ molecule. The subphase portion that has been swept along with the wafer was subsequently sucked off the wafer surface. Post-treatment of the samples was done by immersing them in $1 \mathrm{~mL}$ phosphate buffer $\left(\mathrm{pH}=9,0.1 \mathrm{wt} \% \mathrm{H}_{2} \mathrm{O}_{2}\right)$ each and storing them at 5 ${ }^{\circ} \mathrm{C}$ overnight.

AFM Analysis. AFM analysis was performed on a Bruker Dimension Icon using NanoScope 9.1 for the measurement and NanoScope Analysis 1.5 for image processing. Measurements were performed in tapping mode (in dry or liquid environment) using a $\mathrm{Si}$ tip with a spring constant of $\sim 40 \mathrm{~N} / \mathrm{m}$ and applying a scan rate of 1 Hz.

DERA Quantification. Glass slides being covered with films that contain labeled DERA were first transferred to a 24-well microtiter plate and analyzed using a Tecan infinite M200 Pro microplate reader. Excitation wavelength was set $650 \mathrm{~nm}$ and emission was detected at $684 \mathrm{~nm}$, recording 6 data points within $25 \mathrm{~min}$ which were then averaged. After that each slide was covered with $1 \mathrm{~mL}$ pf phosphate buffer ( $\mathrm{pH} 9)$ within the well and stored overnight at $5{ }^{\circ} \mathrm{C}$. Subsequently, the plate was subjected to ultrasonication for $60 \mathrm{~min}$ at room temperature, the slides were taken out from the respective solutions and transferred to separate wells and fluorescence analysis was repeated both on the solutions as well as on the slides. For calibration a dilution row of the labeled DERA in the same buffer was prepared and pretreated in exactly the same manner as the solutions to be analyzed.

Activity Assay. For activity studies, glass slides, being covered with the DERA containing films, were transferred to a 24-well microtiter plate. To each well, $978 \mu \mathrm{L}$ TEA buffer $(0.1 \mathrm{M}, \mathrm{pH}=7.0), 11 \mu \mathrm{L}$ of BSA in Milli-Q $(40 \mathrm{mg} / \mathrm{mL})$ and $11 \mu \mathrm{L}$ of substrate stock solution in phosphate buffer (4-methylumbelliferone-coupled D-xylose, $10 \mathrm{mM}$ ) were added. For comparison with the specific activity of DERA in solution, $3 \mu \mathrm{L}$ of the TEA buffer portion were replaced by a DERA stock solution in phosphate buffer $(1 \mathrm{mg} / \mathrm{mL})$ and a blank glass slide was used. Fluorescence of each well was measured at appropriate time intervals using the Tecan infinite M200 Pro microplate reader with an excitation wavelength of $360 \mathrm{~nm}$ and emission wavelength of $460 \mathrm{~nm}$. Each time, 6 data points were recorded within $25 \mathrm{~min}$ and averaged. Values recorded for the blank sample were subtracted from the other traces. For calibration, fluorescence intensities from a dilution row of 4-methylumbelliferone ranging from 1 to $50 \mu \mathrm{M}$ were recorded.

Contact Angle Measurements. Contact angle analysis was performed on a DataPhysics OCA 25 device utilizing the software SCA 22 for data recording and processing. For each sample, droplets of 5 $\mu \mathrm{L}$ of the respective buffer were applied and a 2-point measurement was performed.

\section{RESULTS AND DISCUSSION}

The generation of ultrathin layers by self-assembly processes of suitable compounds (e.g., amphiphilic molecules, block copolymers, polar polymers) at the air-water interface by the Langmuir technique is of utmost importance. It offers the opportunity to create ultrathin functional films that can be compressed and transferred in a very controlled fashion. Polymers as film building material are advantageous over low molecular weight (MW) amphiphilic compounds, since they mostly form films with higher mechanical stability. ${ }^{36}$ As in the case of the lower MW amphiphiles, suitable polymers must show a certain polarity gradient in their chemical structure in order to exhibit the required surface activity. Typically, this is solved by using amphiphilic block copolymer structures, ${ }^{37,38}$ which, however, are more complex in their fabrication compared to homopolymers or statistical copolymers and might show unwanted microphase separation in the lateral dimension. ${ }^{39-41}$ Homopolymers and statistical copolymers on the other hand are also able to form defined and stable Langmuir films as long as a limited water solubility is maintained. Here the required polarity gradient is established along the repeating unit of the polymer chain. The limited solubility, however, is an issue for the subsequent use of the film as biocatalytically active membrane layer as this purpose requires the ability of the enzyme accommodating matrix to swell in water. For this reason, we chose a PNIPAAm-based polymer equipped with $31 \mathrm{~mol} \%$ of a thiolactone containing comonomer. Such a composition renders the polymer insoluble in water even at temperatures close to the freezing point. ${ }^{34} \mathrm{~A}$ hydrolysis of the thiolactone units, however, introduces carboxy groups to the polymer which in turn causes a tremendous hydrophilization of the polymer. Furthermore, thiol groups are released that can be used to form disulfide bridges for crosslinking or sulfonate groups to boost the hydrophilization. Last but not least, the thiolactone can also be attacked by primary amino groups, which is utilized here to achieve a covalent binding of DERA to the film via the lysine groups of the enzyme and to firmly tether the film to an amino-functionalized support after the transfer step. The polymer itself is easily synthesized by RAFT following a previously established procedure $^{34}$ Polymer specifications are listed in the Experimental Section.

Film Formation and Transfer. The first step involves the generation of the polymer film at the air-water interface and the demonstration of a successful film transfer, hydrophilization and cross-linking. The subphase in use is a $20 \mathrm{mM}$ potassium phosphate buffer set to a $\mathrm{pH}$ of 7.0. The presence of electrolytes in the subphase definitely has an impact on the surface activity of the polymer and the enzyme. However, the 
subphase has not been altered throughout the entire investigations except for selected experiments that have been performed for comparison reasons. Figure 1A shows three

A)

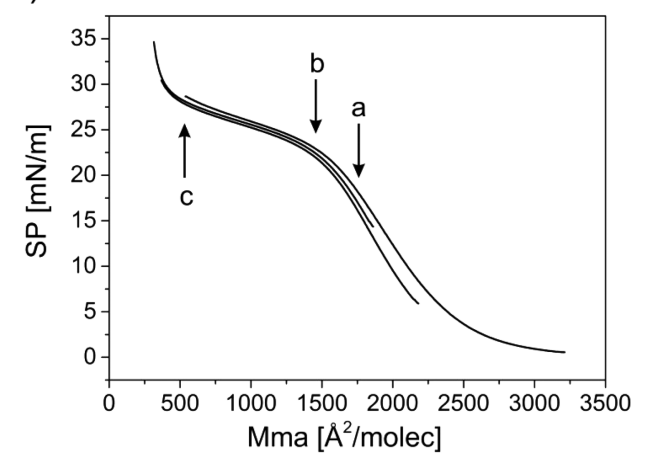

B)

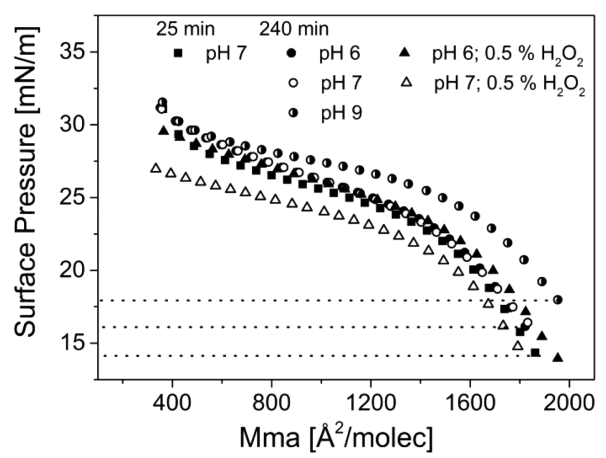

Figure 1. Isotherms recorded for $\mathrm{p}$ (NIPAAm-co-TlaAm) (rel. $\mathrm{MW}=$ $12.4 \mathrm{~kg} / \mathrm{mol} ; \mathrm{PDI}=1.34$; TlaAm content $31 \mathrm{~mol} \%$ ) on phosphate buffer; $T=25{ }^{\circ} \mathrm{C}$. A) superimposed isotherms recorded after a waiting time of 25 min after spreading; the marked spots correspond to the positions at which IRRA spectra were taken (Figure S3). (B) Isotherms recorded with different subphase conditions (see graph legend) after a waiting time of $240 \mathrm{~min}$ after spreading. superposed isotherms recorded for the polymer, starting with different amounts of spread material and thus different initial surface pressures. One single isotherm covering the whole mean molecular area ( $\mathrm{mma}$ ) range could not be generated due to the limited compression ratio of the trough. Therefore, different spreading volumes have been used to generate the different parts of the isotherm. Infrared reflection-absorption spectroscopy (IRRAS) measurements, which will be discussed later in this section, indicate that even the spreading of the largest amount of material does not lead to an overcrowding of the surface and in turn a heterogenic distribution of material. The small differences in the mma between the compression curves in Figure 1A are thus within the expected error bars. The features of the isotherms will only briefly be described as a more detailed analysis is out of scope of the current contribution and will be addressed in forthcoming work. Note that the mma values are apparent ones as the determined molecular weight of the polymer is not absolute. As can be seen, a first significant rise of the surface pressure occurs at an apparent mma of around $3000 \AA^{2} /$ molec followed by a plateau starting at $1500 \AA^{2} / \mathrm{molec}$, and a second rise at around $500 \AA^{2} /$ molec. Additionally, a relaxation back to the surface pressure level of the plateau occurs after the barriers are stopped (Figure S6). IRRAS-measurements show that the plateau is a result of a transition that causes a strong increase in film thickness (Figure S3). Saito et al., who investigated PNIPAAm films at a temperature where the polymer becomes insoluble, which resembles our system-claimed, that the increase in thickness originates from a portion of adsorbed polymer chains dangling into the subphase upon compression. ${ }^{42}$ Indeed, the fitting of data obtained from angle dependent IRRAS revealed a thickness increase from around 1.5 to $3 \mathrm{~nm}$ with a slightly increasing refractive index, which fits to a conformational change from rather stretched, fully adsorbed chains to more coiled structures with dangling loops. However, as long as the plateau is not reached, the stretched polymer conformation is maintained, which is supported by only slight differences in the $\mathrm{OH}$-band intensity, indicating only an increasing packing density but no increase in layer thickness (Figure S3). The

Scheme 2. Chemical Reactions Occurring in the DERA-Containing Polymeric Film upon Post-treatment in $\mathrm{pH}=9 \mathrm{Phosphate}$ Buffer in the Presence of $\mathrm{H}_{2} \mathrm{O}_{2}$

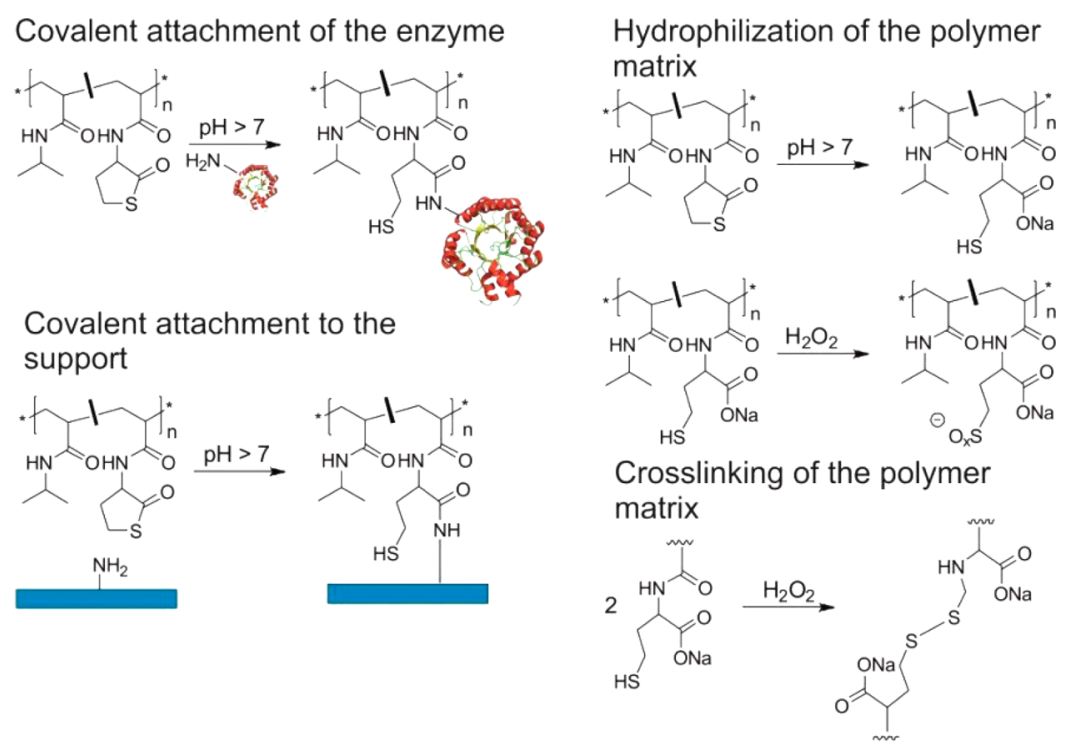


absence of any conformational transition in turn indicates that the surface is far from being overcrowded with material below the plateau. The observed relaxation after barrier stop, which is only taking place at high SP (Figure S6), is most likely attributed to an ongoing chain (segment) desorption into the subphase after cessation of compression until a stable SP level is reached. ${ }^{42}$

A pH of 7 can be normally considered high enough to induce hydrolysis of the thiolactone units, while a $\mathrm{pH}$ of 6 is still too low for that reaction to occur at a measurable rate. ${ }^{43}$ So the question arises, whether a beginning hydrolysis compromises the film stability with time when working with a neutral subphase, as we do. To answer that question, we recorded several isotherms with different subphase conditions, keeping the amount of spread polymer constant throughout the entire set of experiments (Figure 1B). For $\mathrm{pH}=6$ and $\mathrm{pH}=7$, the isotherms remain almost unaltered after a waiting time of $4 \mathrm{~h}$, while at $\mathrm{pH}=9$, the initial surface pressure and the plateau level have risen significantly. The initial SP rise is a sign for a higher demand of space per polymer chain, which could originate from the repulsive forces of charged carboxy groups that are introduced upon hydrolysis. At the same time, the increase in hydrophilicity of the polymer is not yet sufficient enough to induce an increased level of chain segment desorption into the subphase which would counteract this rise. To trigger an enhanced hydrophilization that would allow for the exploration of a regime in which the film stability starts to get significantly compromised, we also added $\mathrm{H}_{2} \mathrm{O}_{2}$ to the subphase. $\mathrm{H}_{2} \mathrm{O}_{2}$ causes a partial oxidation of the thiol groups that get released upon hydrolysis. By that, sulfonate groups are created (Scheme 2) which apparently boosts the hydrophilization to an extent that it compensates for the SP rise and lets the plateau even drop to a lower level than the initial one. Note that this occurs already at $\mathrm{pH}=7$, where we did not observe any significant changes before. This can only mean, that $\mathrm{H}_{2} \mathrm{O}_{2}$, at $\mathrm{pH}=7$, also boosts the hydrolysis itself because of an equilibrium shift. At $\mathrm{pH}=6$, this effect is apparently absent emphasizing the necessity of a certain threshold $\mathrm{pH}$ to induce hydrolysis. Yet, in the absence of any additional reagent, a $\mathrm{pH}$ of 7 is still not too high to have a negative effect on film stability, which is an important factor for the establishment of proper conditions during the enzyme immobilization step later on.

Film transfer, after full compression and relaxation of the film, occurs via a simple horizontal dipping (LangmuirSchaefer) of amino functionalized glass slides or silicon wafers onto the surface. After the subphase portion that has been swept along with the film has been removed from the wafer by suction, the dipping can be repeated, building up films with varying thicknesses, with the latter linearly depending on the number of dipping cycles (Figure 2B). Note that the compressed film is rather brittle, leaving cracks after the transfer as can be seen in a respective optical microscope image (Figures 2A and S9). The brittleness on the other hand allows to dip the wafer several times on different positions of the Langmuir trough without causing a significant decrease in surface pressure. In other words, the dipping simply leaves a hole in the film that is not closed immediately.

Post-treatment of the transferred film with $20 \mathrm{mM}$ potassium phosphate buffer at $\mathrm{pH} 9$ and $5{ }^{\circ} \mathrm{C}$ in the presence of $0.1 \mathrm{wt} \%$ $\mathrm{H}_{2} \mathrm{O}_{2}$ is supposed to fully hydrophilize and cross-link the film. While the basic environment causes an accelerated hydrolysis of the thiolactone units, the $\mathrm{H}_{2} \mathrm{O}_{2}$ will not only generate sulfonate, as already mentioned, but also disulfide groups. XPS studies
A)
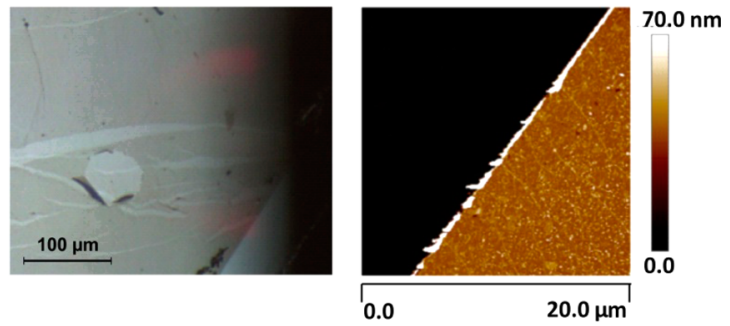

B)

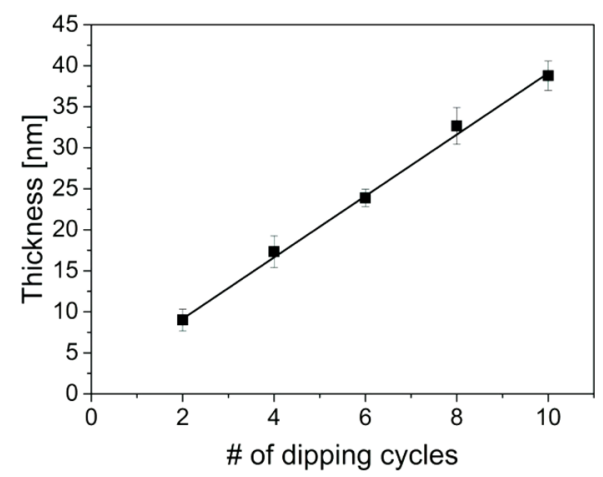

Figure 2. p(NIPAAm-co-TlaAm) film prepared and transferred to an amino-functionalized Si-wafer via the Langmuir-Schaefer technique: (A) Optical microscope and AFM topography image of a film build up by 10 consecutive dippings and (B) plot of film thickness determined by AFM as a function of the number of dippings per wafer.

show, that approximately only half of all thiol groups reach a higher oxidation state affiliated to sulfonate moieties (Figure S4), the rest remains unoxidized or forms disulfide bonds. A successful hydrophilization is confirmed by contact angle measurements and AFM studies. As the hydrolysis step introduces carboxyl groups to the polymer film, contact angles and swelling degrees become $\mathrm{pH}$-dependent. Figure 3 shows a decrease of the contact angle from around $70^{\circ}$ to $45^{\circ}$ for a posttreated film when switching from $\mathrm{pH} 2$ to $\mathrm{pH} 7$. By AFM one can also clearly see the strong increase in film thickness upon
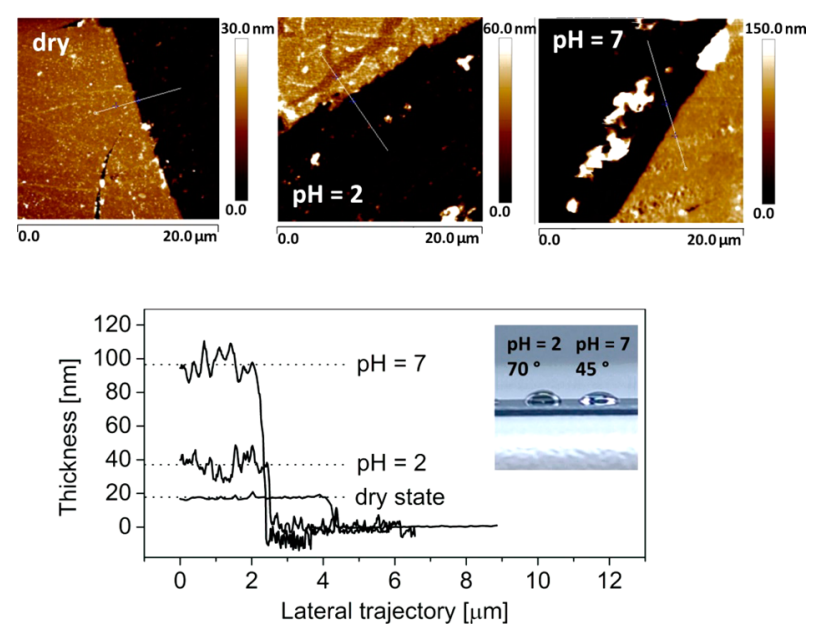

Figure 3. AFM topography images and corresponding section analysis of a post-treated $\mathrm{p}(\mathrm{NIPAAm}-\mathrm{co}-\mathrm{TlaAm})$ film deposited onto an amino-functionalized Si-wafer. The inset in the section analysis graph shows the change of the contact angle of the films upon $\mathrm{pH}$ change. 
the $\mathrm{pH}$ switch. The deprotonated and therefore charged carboxyl groups at $\mathrm{pH} 7$ cause a strong repulsion between the chains and so a significant increase in the swelling ratio.

DERA Binding, Binding Mechanism, and Film Stability. With the polymer film formed, DERA can now be injected into the subphase, adsorb to the film, and bind to it. DERA itself appears in its natural, active form as a water-soluble, globular protein being stable within a $\mathrm{pH}$ range of $5.5-10 .{ }^{44} \mathrm{In}$ fact, only a small hydrophobic patch exists on its surface, which should not be sufficient in size to induce a strong amphiphilicity (Figure S10). Still, like many other water-soluble proteins it adsorbs to the air-water interface as evidenced by the isotherm recorded after a certain waiting time after injection of the enzyme into the subphase (Figure S7). A large number of scientific contributions address the question to what extent protein molecules unfold when being adsorbed at the interface with rather diverse conclusions. ${ }^{45}$ However, the fact that the pure DERA Langmuir film that is obtained after compression exhibits a high SP that remains stable over a prolonged time period suggests that the desorption kinetics is very slow. From a thermodynamical point of view, an adsorption layer of amphiphilic compounds is in equilibrium if the adsorption and desorption rates are the same. Such a layer, however, cannot be compressed to higher surface pressures. Therefore, protein adsorption layers are usually not in a thermodynamical equilibrium because of changed structures resulting in extremely slow desorption rates. This in consequence supports the hypothesis of a conformational change of the DERA structure upon adsorption ${ }^{22,23}$ and in turn emphasizes the need of an enzyme accommodating matrix layer.

DERA can be injected into the subphase before or after compression of the polymer film and so adsorb to the film at different stages of compression. Two runs were performed where the injection is accomplished before the SP plateau is reached, at 8 (A) and $15 \mathrm{mN} / \mathrm{m}$ (B), respectively (Table 1). For the third run, the injection was done at full compression of the film (C), that is, where the surface is more or less fully occupied by polymer, constituting a rather dense film that has chain segments dangling into the subphase. In each case, a waiting time of $90 \mathrm{~min}$ has been established followed by a final compression of the partially compressed films. Transfer to a

Table 1. Summary of the DERA Containing Polymer Films That Have Been Prepared Including Information on the Preparation Route, Determined Enzyme Fractions, and Enzymatic Activities

\begin{tabular}{|c|c|c|c|}
\hline sample & $\begin{array}{l}\text { point of DERA } \\
\text { injection }\end{array}$ & $\begin{array}{c}\text { fraction of DERA in the } \\
\text { film fluorescence/XPS } \\
{[\%]}\end{array}$ & $\begin{array}{l}\text { activity of } \\
\text { the film } \\
{[\mu \mathrm{M} / \mathrm{h}]}\end{array}$ \\
\hline A & $\begin{array}{l}\text { before plateau }^{b} \\
\qquad(\Pi=8 \mathrm{mN} / \mathrm{m})\end{array}$ & $42 / 46 ; 62$ & 0.015 \\
\hline B & $\begin{array}{l}\text { before plateau }^{b} \\
\quad(\Pi=15 \mathrm{mN} / \mathrm{m})\end{array}$ & $28 /-$ & 0.01 \\
\hline $\begin{array}{l}\text { B, no post- } \\
\text { treatment }^{a}\end{array}$ & $\begin{array}{l}\text { before plateau }{ }^{b} \\
\quad(\Pi=15 \mathrm{mN} / \mathrm{m})\end{array}$ & $28 /-$ & 0.002 \\
\hline $\mathrm{C}$ & $\begin{array}{l}\text { after plateau } \\
\quad(\Pi \approx 30 \mathrm{mN} / \mathrm{m})\end{array}$ & $18 /-$ & 0.005 \\
\hline
\end{tabular}

${ }^{a}$ Conditions for post-treatment see Experimental Section. ${ }^{b}$ The term "plateau" refers to the feature of the polymer isotherm between 1500 and $500 \AA^{2} /$ molec (Figure 1A). ${ }^{c}$ Conditions see Experimental Section and Supporting Information. ${ }^{d} 1 \times 1 \mathrm{~cm}$ glass slide equipped with 8 layers of polymer/DERA film $(\sim 3.3 \mu \mathrm{g}$ material $)$ and immersed in 1 $\mathrm{mL}$ substrate solution (see Experimental Section). silicon or glass support was accomplished in the same manner as before for the pure polymer films. Note that the loading of the film with enzyme does not significantly affect the film thickness and transferability. In the cases where DERA has been injected before the SP plateau, adsorption of the enzyme could be nicely followed by a significant increase in SP (Figure S8), which shows that DERA directly inserts into the polymer film when the latter is still expanded. Consequently the different injection points should lead to different enzyme loadings, which can be explained by two counteracting effects. The higher the initial SP upon enzyme injection, the higher the initial film density and thus, the lower the fraction of enzyme that can accommodate within the film. On the other hand, the enzyme should have a better accessibility to the desorbed chain fragments that occur at a high degree of film compression. To determine the fractions of enzyme in the transferred films, DERA was labeled with a maleimide functionalized fluorescent dye via Michael addition prior to use. Using nonfunctional glass slides for deposition this time, the deposited layers could be washed off after the post-treatment step by shaking and ultrasonication. Washing solutions were then checked for fluorescence. Quantification was achieved by comparing the measured fluorescence with the values determined for a dilution series of the labeled enzyme in solution (Figure 4). Each

A)

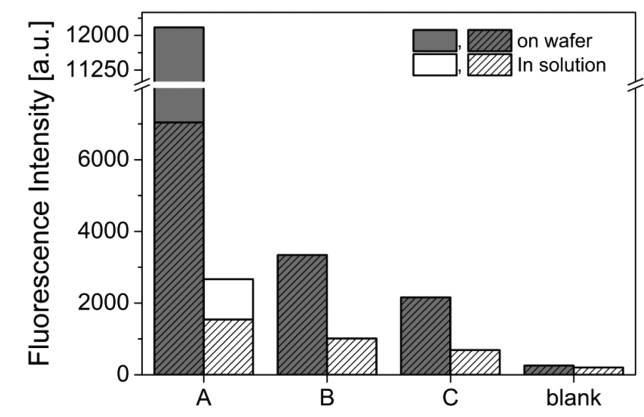

B)

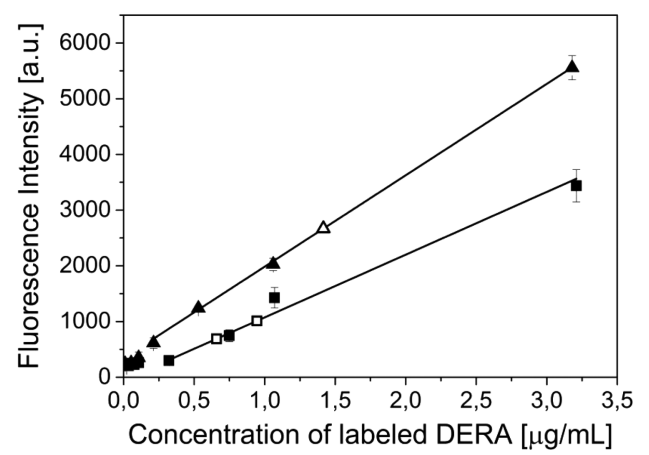

Figure 4. Estimation of DERA contents in the transferred films by fluorescence analysis on samples that contain labeled enzyme: (A) Fluorescence intensities measured on the deposited films and respective aqueous solutions that result when the material is washed off from the glass supports. The column inscriptions refer to the preparation route of the films (see Table 1). For sample A, in which a different batch of labeled DERA was used, obtained values were normed for comparison. (B) Corresponding calibration functions, the open symbols represent the solution samples presented in panel A. 
sample was composed of a glass slide with an area of $1 \times 1 \mathrm{~cm}^{2}$ being covered with 8 layers of enzyme loaded film. Assuming a film density of $1.05 \mathrm{~g} / \mathrm{cm}^{3}$, a value that is given for physisorbed, collapsed PNIPAAm chains above the LCST, ${ }^{46}$ and taking into account a thickness of a single layer of $3.9 \mathrm{~nm}$ (from AFM analysis), the total amount of deposited material per sample is roughly $3.3 \mu \mathrm{g}$. Fluorescence analysis of the washing solutions give amounts of enzyme ranging from 0.6 to $1.4 \mu \mathrm{g}$. In consequence, the enzyme containing films show enzyme loadings from $18 \%$ to $42 \%$ with the values decreasing from sample A over sample B to C. These findings indicate, that the attachement of DERA to the desorbed chain segments within the subphase is not as effective as the direct insertion into the film when the latter is still expanded.

As the labeled DERA shows slightly decreased surface activity compared to the nonlabeled enzyme, slight deviation from the real values can be expected. Therefore, we also performed XPS measurements of films loaded with nonlabeled DERA to confirm the degree of loading (Table 1). As the polymer exhibits a much higher fraction of sulfur atoms than DERA (1.6 mol \% for the polymer but only $0.26 \mathrm{~mol} \%$ for DERA; protein sequence see $\mathrm{SI}$ ), quantitative analysis can be performed by determining the amount of sulfur in the films. The lower the sulfur content, the higher the enzyme loading. While the sulfur to carbon $(\mathrm{S} / \mathrm{C})$ ratio for a pure DERA film was determined with 0 and 0.009 (repeat), the pure polymer film showed a S/C ratio of 0.028 and 0.033 . Reliable values for quantification of the DERA content in the mixed films, unfortunately, were only achieved for the sample with the highest enzyme loading, that is, strongest deviation from the sulfur content of the pure polymer as respective signals in XPS are rather weak (Figure S5). Nevertheless, a drop of the S/C value to approximately half of the original value for the pure polymer layer supports the initial finding that the film with the highest enzyme loading (sample A, Table 1) is composed of roughly one-half by enzyme.

A point that has not been addressed so far is the question by which mechanism DERA binds to the film upon adsorption and whether we indeed achieve covalent binding of the enzyme. The theoretical isoelectric point of DERA is $5.62,{ }^{47}$ meaning that the enzyme bears a slightly negatively charged surface under the conditions established for the film formation. Although the polymer also should be rather negatively charged, especially after the post-treatment step (remember the hydrolysis), it is reported that in such a system, attractive forces can dominate, originating for instance from hydrogen bonding. ${ }^{48}$ A first hint is given when comparing the standard film formation procedure to a procedure where Milli-Q water is used as subphase. It occurs that a significantly lower amount of DERA is bound in that case, although this amount is still not zero (Figure S11). At the slightly acidic conditions of Milli-Q water, hydrolysis and aminolysis of the thiolactone units are widely suppressed, ${ }^{43}$ therefore, DERA can only physically attach to the polymer in that case. Of course, Milli-Q does not only differ in $\mathrm{pH}$ but also in ionic strength compared to the buffer used otherwise, so an altered adsorption behavior of polymer and enzyme could also explain the difference. Therefore, additional experiments were carried out. Samples prepared with $\mathrm{pH} 7$ and $\mathrm{pH} 5.75$ buffers (with the same ionic strength) as well as Milli- $\mathrm{Q}$ water as subphase have been immersed in salt free, acidic water $(\mathrm{pH}=2)$ right after their preparation (no additional hydrophilization/cross-linking posttreatment) and been shaken for several hours at low temperature. Under these conditions the polymer should be soluble and carry no negative charge (as the carboxy groups should be largely protonated under these conditions). As it turns out, significantly more material is left on the support for the sample that has been prepared at $\mathrm{pH}=7$ than for the other samples (Figure 5). As one DERA molecule carries 19 lysine

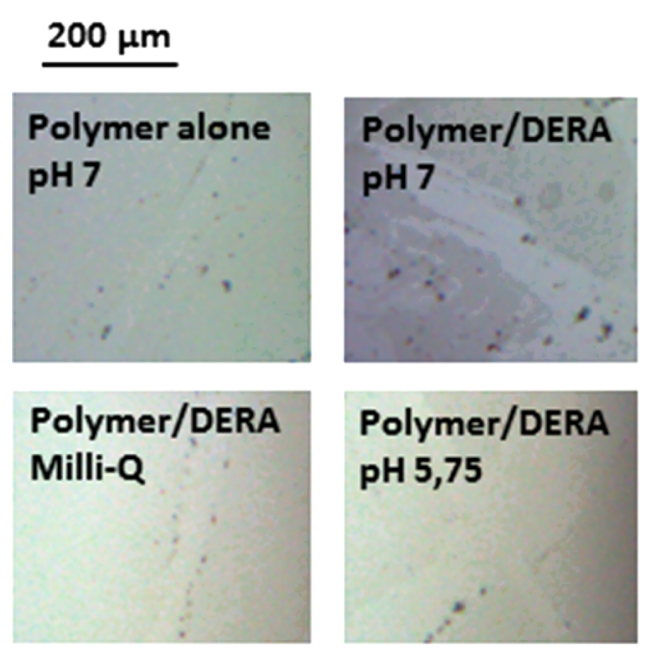

Figure 5. Optical microscope images of DERA containing p(NIPAAm-co-TlaAm) films that have been subjected to shaking in $\mathrm{pH}=2$ aqueous solutions at $5{ }^{\circ} \mathrm{C}$ for several hours right after the deposition. The contrasts between the blank areas and the film areas are directly correlated to the remaining film thicknesses. The graph legends refer to the preparation conditions of the films (for mixed films, preparation was done according to sample B, Table 1).

units and therefore can act as cross-linker when it reacts with the thiolactone groups, it is likely, that it indeed attached covalently to the film upon adsorption, at least partially. The cross-linking effect of DERA becomes even more obvious after a modified post-treatment step $\left(\mathrm{pH}=9\right.$, but no $\left.\mathrm{H}_{2} \mathrm{O}_{2}\right)$, as the reaction of the enzyme with the thiolactone units is boosted at elevated $\mathrm{pH}$. As can be seen from Figure 6, exposure to basic environment leaves much more material behind when DERA is present. Note that this effect does not occur for sample C, where the preformed polymer film was already so dense that DERA could not be accommodated between the polymer chains but only attach to the desorbed, dangling loops. It is noted that the addition of $\mathrm{H}_{2} \mathrm{O}_{2}$ in the post-treatment step is still worthwhile not only for sample $\mathrm{C}$ because of the increased hydrophilization (see previous section) but also because the deposited film appears even more stable then, as evidenced by optical microscope images and fluorescence studies (Figure 6). Note that in case where most material is washed off, still film material is visible, meaning that at least one layer remains, which supports a successful binding of the polymer to the support (Figure 5).

Activity Assay. As a final step, the enzyme activity of the prepared films has to be confirmed and quantified. For that purpose, a self-designed activity assay based on the release of a fluorescent dye upon a DERA-catalyzed retro aldol reaction was employed. ${ }^{33}$ The freshly prepared glass slides where immediately subjected to the post-treatment procedure followed by immersion into a $\mathrm{pH}=7$ triethanolamine buffer that contains the substrate and bovine serum albumin (BSA). The latter acts as a weak base, promoting the cleavage of the fluorescent dye 4methylumbelliferone from the retro-aldol product of the 
A)

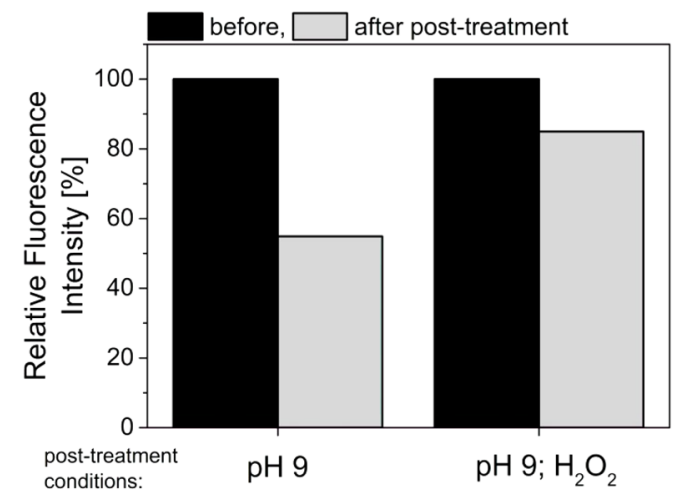

B)

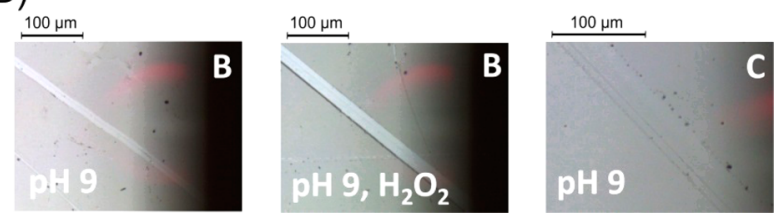

Figure 6. Assessment of film stability under post-treatment conditions (details see Experimental Section): (A) Fluorescence intensities measured on DERA containing p(NIPAAm-co-TlaAm) films (prepared by route $\mathrm{B}$, Table 1 ; deposition on glass slides) before and after the post-treatment step (general conditions according to column inscription). (B) Optical microscope images of respective films deposited on Si-wafers (the lower left corner indicates the posttreatment conditions, while the preparation route is indicated in the upper left corner of each image; see Table 1). The contrasts between the blank areas and the film areas are directly correlated to the thicknesses of the remaining material.

enzymatic conversion. ${ }^{49}$ Since the substrate is prone to autodecomposition, fluorescence increase is also detectable in the absence of DERA. Therefore, a reference sample, being a blank glass slide, was also monitored (Figure 7A). For a couple of days, no difference between the reference and the DERA containing specimens was detectable pointing to DERA being more or less completely deactivated upon immobilization at a first glance. However, after that period, deviations from the reference sample start to occur, with the slopes of the fluorescence increase being directly correlated to the fractions of enzyme in the polymer film. This not only indicates that DERA is still active after immobilization, but also that it is irrelevant wether DERA has been inserted directly into the film during the preparation process (route $\mathrm{A}$ and $\mathrm{B}$, Table 1 ) or wether it simply attached to the desorbed polymer segments (route $\mathrm{C}$ ). Another feature being detectable is the fact that full activity apparently is reached only when the film has become fully hydrolyzed in the post-treatment step. Another film that has been subjected to the activity assay right after the film deposition without post-treatment shows significantly decreased activity. This finding emphasizes the importance of polymer film hydrolysis prior to its application. Last but not least, we can also prove, that almost no enzyme is leaking out of the film during the somewhat prolonged activity study as evidenced by the fact, that activity more or less ceases as soon as the glass slides are taken out from their respective solutions. Only in the case of the highest enzyme loading, fluorescence is increasing further, though with a strongly decreased rate. Unfortunately, the pronounced induction period cannot be
A)

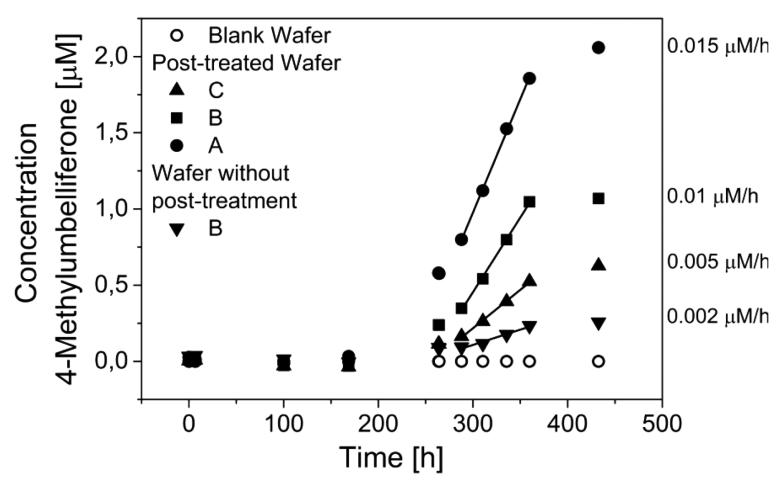

B)

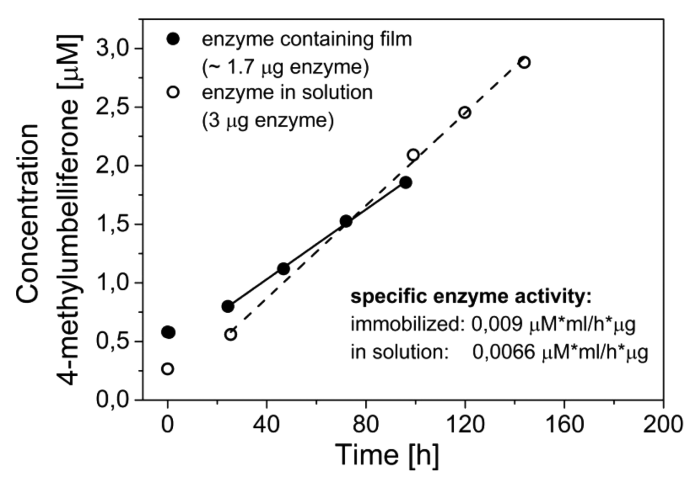

Figure 7. (A) Concentration of 4-methylumbelliferone as a function of time in substrate solutions into which glass slides being decorated with DERA containing $\mathrm{p}$ (NIPAAm-co-TlaAm) films have been immersed. (B) Comparison of the specific enzyme activities for immobilized DERA and DERA in solution (values taken from sample A). Time $=0$ $\mathrm{h}$ has been set to the point where the onset of activity occurs, respectively.

explained so far. One reason could be substrate inhibition due to the small amount of enzyme present, since an induction period is also detectable for the enzyme in solution (Figure S12). Yet, the time period with no activity is much longer for the immobilized enzyme, so other effects must come into play. As the occurrence and the duration of this induction period does not depend on the exact assay conditions $(\mathrm{pH}$, substrate concentration, presence of BSA) or the amount of immobilized enzyme (Figure 7A), the most reasonable explanation for it is a reversible deactivation of the enzyme during the immobilization and transfer process. Of course, one might be tempted to link this deactivation to a conformational change of the enzyme during its adsorption to the interface. However, one should not forget that the deactivation occurs also for samples where the enzyme had no opportunity to adsorb directly to the interface (preparation route $\mathrm{C}$, Table 1 ). Besides, a refolding of a protein molecule that is entrapped in a polymeric network seems highly unlikely. The exact mechanism of deactivation therefore remains a subject for further investigation.

Apart from the induction period, the question arises, how the specific enzyme activity has evolved upon immobilization. To answer this question, the activity assay has also been performed for the enzyme in solution with a comparable amount of enzyme. Figure $7 \mathrm{~B}$ shows that the specific activity of the immobilized enzyme appears to be higher than the activity of 
the enzyme in solution, taking into account that the quantification of the enzyme fraction in the film, which had been done before, only allows for a rough comparison. Nevertheless, it is safe to conclude, that the specific enzyme activity is not significantly affected upon immobilization. Note that the use of $\mathrm{H}_{2} \mathrm{O}_{2}$, which enhances hydrophilization and cross-linking of the polymer matrix, has no effect on the immobilized enzyme, although it leads to a significantly decreased specific activity for DERA in solution (Figure S12).

\section{CONCLUSION}

We demonstrated how 2-deoxy-D-ribose-5-phosphate aldolase can be immobilized in a thin polymeric film that is deposited on a suitable support without significantly altering the enzymes specific activity. The polymeric film has first been generated at the air-water interface from a PNIPAAm based, thiolactone carrying copolymer showing limited water solubility using the Langmuir technique. Before transferring the film to a silicon or glass support, DERA was allowed to attach by injecting it into the subphase. We were able to show, that we can easily tune the film in thickness and enzyme loading while proving a covalent binding of the enzyme to the matrix and a successful posttreatment that renders the film hydrophilic and induces additional cross-links for increased stability. In the future, further investigations are necessary on the origin of the prolonged induction period that was observable during the assessment of the enzyme activity in the deposited films. As this period seems to stem from the immobilization procedure itself, knowing the origin of it would help to find a way to eliminate it through a systematic adjustment of the preparation conditions.

\section{ASSOCIATED CONTENT}

\section{S Supporting Information}

The Supporting Information is available free of charge on the ACS Publications website at DOI: 10.1021/acsami.6b13632.

Data on NMR and SEC analysis of the used polymer, data on IRRAS measurements of the polymer film at the air-water interface, as well as additional information on DERA $_{\mathrm{EC}}$, supplemental data on XPS and AFM, supplemental isotherms and other surface pressure recordings, supplemental fluorescence studies of the enzyme containing films and supplemental enzyme activity data (PDF)

\section{AUTHOR INFORMATION}

\section{Corresponding Author}

*E-mail: Stefan.Reinicke@iap.fraunhofer.de.

ORCID ${ }^{\circ}$

Stefan Reinicke: 0000-0002-3666-6504

Filip E. Du Prez: 0000-0003-4065-6373

Jörg Pietruszka: 0000-0002-9819-889X

Alexander Böker: 0000-0002-5760-6631

\section{Author Contributions}

The manuscript was written through contributions of all authors. All authors have given approval to the final version of the manuscript.

\section{Funding}

This work was supported by the Ministry of Innovation, Science and Research within the framework of a seed fund research grant of the Bioeconomy Science Center Consortium of the federal state of North Rhine Westphalia, Germany (No.
313/323-400-002 13). Markus Dick received a scholarship from the Heinrich-Heine-Universität Düsseldorf within the framework of the iGRASPseed-Graduate Cluster.

\section{Notes}

The authors declare no competing financial interest.

\section{ACKNOWLEDGMENTS}

The authors thank Dr. Andreas Holländer of the Fraunhofer Institute of Applied Polymer Research for the aid regarding the XPS measurements and Falko Rottke of the Helmholtz-Centre for Materials and Coastal research for performing refractive index measurements.

\section{ABBREVIATIONS}

DERA = 2-deoxy-D-ribose-5-phosphate aldolase

NIPAAm $=N$-isopropylacrylamide

TlaAm $=N$-(2-thiolactone) acrylamide

$\mathrm{SP}=$ surface pressure

BSA $=$ bovine serum albumin

APTES = 3-aminopropyltriethoxysilane

XPS $=$ X-ray photoelectron spectroscopy

TEA $=$ triethanolamine

$\mathrm{MW}=$ molecular weight

$\mathrm{mma}=$ mean molecular area

\section{REFERENCES}

(1) Sheldon, R. A. Enzyme Immobilization: The Quest for Optimum Performance. Adv. Synth. Catal. 2007, 349, 1289-1307.

(2) Tran, D. N.; Balkus, K. J. Perspective of Recent Progress in Immobilization of Enzymes. ACS Catal. 2011, 1, 956-968.

(3) Garcia-Galan, C.; Berenguer-Murcia, Á.; Fernandez-Lafuente, R.; Rodrigues, R. C. Potential of Different Enzyme Immobilization Strategies to Improve Enzyme Performance. Adv. Synth. Catal. 2011, 353, 2885-2904.

(4) Hanefeld, U.; Gardossi, L.; Magner, E. Understanding Enzyme Immobilisation. Chem. Soc. Rev. 2009, 38, 453-468.

(5) Storhas, W. Bioverfahrensentwicklung; Wiley-VCH Verlag GmbH, 2003.

(6) Jochems, P.; Satyawali, Y.; Diels, L.; Dejonghe, W. Enzyme Immobilization on/in Polymeric Membranes: Status, Challenges and Perspectives in Biocatalytic Membrane Reactors (BMRs). Green Chem. 2011, 13, 1609-1623.

(7) Giorno, L.; Drioli, E. Biocatalytic Membrane Reactors: Applications and Perspectives. Trends Biotechnol. 2000, 18, 339-349.

(8) Rios, G. M.; Belleville, M. P.; Paolucci, D.; Sanchez, J. Progress in Enzymatic Membrane Reactors - a Review. J. Membr. Sci. 2004, 242, $189-196$

(9) Britton, J.; Raston, C. L.; Weiss, G. A. Rapid Protein Immobilization for Thin Film Continuous Flow Biocatalysis. Chem. Commun. 2016, 52, 10159-10162.

(10) Schaeffer, J. R.; Burdick, B. A.; Abrams, C. T. Thin-Film Biocatalysts. CHEMTECH 1988, 18, 546-550.

(11) Rusling, J. F.; Hvastkovs, E. G.; Hull, D. O.; Schenkman, J. B. Biochemical Applications of Ultrathin Films of Enzymes, Polyions and DNA. Chem. Commun. 2008, 14, 141-154.

(12) Rusling, J. F.; Wasalathanthri, D. P.; Schenkman, J. B. Thin Multicomponent Films for Functional Enzyme Devices and Bioreactor Particles. Soft Matter 2014, 10, 8145-8156.

(13) Davis, F.; Higson, S. P. J. Structured Thin Films as Functional Components Within Biosensors. Biosens. Bioelectron. 2005, 21, 1-20.

(14) Girard-Egrot, A. P.; Godoy, S.; Blum, L. J. Enzyme Association with Lipidic Langmuir-Blodgett Films: Interests and Applications in Nanobioscience. Adv. Colloid Interface Sci. 2005, 116, 205-225.

(15) Rusling, J. F.; Hvastkovs, E. G.; Schenkman, J. B. Toxicity Screening Using Biosensors That Measure DNA Damage. Curr. Opin. Drug Discovery Dev. 2007, 10, 67-73. 
(16) Zayats, M.; Willner, B.; Willner, I. Design of Amperometric Biosensors and Biofuel Cells by the Reconstitution of Electrically Contacted Enzyme Electrodes. Electroanalysis 2008, 20, 583-601.

(17) Bartlett, P. N.; Birkin, P. R. A Microelectrochemica Enzyme Transistor Responsive to Glucose. Anal. Chem. 1994, 66, 1552-1559.

(18) Bartlett, P. N.; Tebbutt, P.; Tyrrell, C. H. Electrochemical Immobilization of Enzymes. 3. Immobilization of Glucose Oxidase in Thin Films of Electrochemically Polymerized Phenols. Anal. Chem. 1992, 64, 138-142.

(19) Bartlett, P. N.; Birkin, P. R.; Wang, J. H.; Palmisano, F.; De Benedetto, G. An Enzyme Switch Employing Direct Electrochemical Communication between Horseradish Peroxidase and a Poly(aniline) Film. Anal. Chem. 1998, 70, 3685-3694.

(20) Neurath, H.; Bull, H. B. The Surface Activity of Proteins. Chem. Rev. 1938, 23, 391-435.

(21) Yano, Y. F.; Arakawa, E.; Voegeli, W.; Matsushita, T. Real-Time Investigation of Protein Unfolding at an Air-Water Interface at the $1 \mathrm{~s}$ Time Scale. J. Synchrotron Radiat. 2013, 20, 980-983.

(22) Tronin, A.; Dubrovsky, T.; Dubrovskaya, S.; Radicchi, G.; Nicolini, C. Role of Protein Unfolding in Monolayer Formation on Air-Water Interface. Langmuir 1996, 12, 3272-3275.

(23) Heitz, F.; Van Mau, N. Protein Structural Changes Induced by Their Uptake at Interfaces. Biochim. Biophys. Acta, Protein Struct. Mol. Enzymol. 2002, 1597, 1-11.

(24) Espeel, P.; Du Prez, F. E. One-Pot Multi-Step Reactions Based on Thiolactone Chemistry: A Powerful Synthetic Tool in Polymer Science. Eur. Polym. J. 2015, 62, 247-272.

(25) Tozzi, M. G.; Camici, M.; Mascia, L.; Sgarrella, F.; Ipata, P. L. Pentose Phosphates in Nucleoside Interconversion and Catabolism. FEBS J. 2006, 273, 1089-1101.

(26) Kierkels, J. G. T.; Mink, D.; Panke, S.; Lommen, F. A. M.; Heemskerk, D. Process for the Preparation of 2,4-Dideoxyhexoses and 2,4,6-Trideoxyhexoses. Int. Patent WO03/006656, 2003.

(27) Heine, A.; DeSantis, G.; Luz, J. G.; Mitchell, M.; Wong, C. H.; Wilson, I. A. Observation of Covalent Intermediates in an Enzyme Mechanism at Atomic Resolution. Science 2001, 294, 369-374.

(28) Wong, C.-H.; Garcia-Junceda, E.; Chen, L.; Blanco, O.; Gijsen, H. J. M.; Steensma, D. H. Recombinant 2-Deoxyribose-5-phosphate Aldolase in Organic Synthesis: Use of Sequential Two-Substrate and Three-Substrate Aldol Reactions. J. Am. Chem. Soc. 1995, 117, 33333339.

(29) Wang, A.; Gao, W.; Zhang, F.; Chen, F.; Du, F.; Yin, X. Amino Acid-Mediated Aldolase Immobilisation for Enhanced Catalysis and Thermostability. Bioprocess Biosyst. Eng. 2012, 35, 857-863.

(30) Subrizi, F.; Crucianelli, M.; Grossi, V.; Passacantando, M.; Botta, G.; Antiochia, R.; Saladino, R. Versatile and Efficient Immobilization of 2-Deoxyribose-5-phosphate Aldolase (DERA) on Multiwalled Carbon Nanotubes. ACS Catal. 2014, 4, 3059-3068.

(31) Nara, T. Y.; Togashi, H.; Ono, S.; Egami, M.; Sekikawa, C.; Suzuki, Y.-h.; Masuda, I.; Ogawa, J.; Horinouchi, N.; Shimizu, S.; Mizukami, F.; Tsunoda, T. Improvement of Aldehyde Tolerance and Sequential Aldol Condensation Activity of Deoxyriboaldolase via Immobilization on Interparticle Pore Type Mesoporous Silica. J. Mol. Catal. B: Enzym. 2011, 68, 181-186.

(32) Fei, H.; Xu, G.; Wu, J.-P.; Yang, L.-R. Improvement of the Thermal Stability and Aldehyde Tolerance of Deoxyriboaldolase via Immobilization on Nano-Magnet Material. J. Mol. Catal. B: Enzym. 2014, 101, 87-91.

(33) Bisterfeld, C.; Küberl née Kullartz, I.; Dick, M.; Pietruszka, J. A Fluorogenic Screening for Enantio- and Diastereoselectivity of 2Deoxy-d-ribose-5-phosphate Aldolases. Synlett 2016, 27, 11-16.

(34) Reinicke, S.; Espeel, P.; Stamenović, M. M.; Du Prez, F. E. OnePot Double Modification of $\mathrm{p}$ (NIPAAm): A Tool for Designing Tailor-Made Multiresponsive Polymers. ACS Macro Lett. 2013, 2, 539-543.

(35) Dick, M.; Weiergräber, O. H.; Classen, T.; Bisterfeld, C.; Bramski, J.; Gohlke, H.; Pietruszka, J. Trading off Stability against Activity in Extremophilic Aldolases. Sci. Rep. 2016, 6, 17908.
(36) Breton, M. Formation and Possible Applications of Polymeric Langmuir-Blodgett Films. A Review. J. Macromol. Sci., Polym. Rev. 1981, 21, 61 .

(37) Draghici, C.; Kowal, J.; Darjan, A.; Meier, W.; Palivan, C. G. Active Surfaces" Formed by Immobilization of Enzymes on SolidSupported Polymer Membranes. Langmuir 2014, 30, 11660-11669.

(38) Ho, D.; Chu, B.; Lee, H.; Montemagno, C. D. Nanoscale Hybrid Protein/Polymer Functionalized Materials. Proc. SPIE 2004, 192-209.

(39) Meszaros, M.; Eisenberg, A.; Lennox, R. B. Block Copolymer Self-assembly in Two Dimensions: Nanoscale Emulsions and Foams. Faraday Discuss. 1994, 98, 283-294.

(40) Wang, X.; Wen, G.; Huang, C.; Wang, Z.; Shi, Y. Aggregation Behavior of the Blends of PS-b-PEO-b-PS and PS-b-PMMA at the Air/ Water Interface. RSC Adv. 2014, 4, 49219-49227.

(41) Cheyne, R. B.; Moffitt, M. G. Novel Two-Dimensional "Ring and Chain" Morphologies in Langmuir-Blodgett Monolayers of PS-bPEO Block Copolymers: Effect of Spreading Solution Concentration on Self-Assembly at the Air-Water Interface. Langmuir 2005, 21, 5453-5460.

(42) Saito, W.; Mori, O.; Ikeo, Y.; Kawaguchi, M.; Imae, T.; Kato, T. Surface Pressure, Ellipsometric, and Atomic Force Microscopic Study of Poly(N-isopropylacrylamide) Film at the Air- Water Interface. Macromolecules 1995, 28, 7945-7946.

(43) Garel, J.; Tawfik, D. S. Mechanism of Hydrolysis and Aminolysis of Homocysteine Thiolactone. Chem. - Eur. J. 2006, 12, 4144-4152.

(44) Sakuraba, H.; Yoneda, K.; Yoshihara, K.; Satoh, K.; Kawakami, R; Uto, Y.; Tsuge, H.; Takahashi, K.; Hori, H.; Ohshima, T. Sequential Aldol Condensation Catalyzed by Hyperthermophilic 2Deoxy-D-Ribose-5-Phosphate Aldolase. Appl. Environ. Microb. 2007, $73,7427-7434$.

(45) Wierenga, A. W.; Egmond, M. R.; Voragen, A. G. J.; de Jongh, H. H. J. The Adsorption and Unfolding Kinetics Determines the Folding State of Proteins at the Air-Water Interface and Thereby the Equation of State. J. Colloid Interface Sci. 2006, 299, 850-857.

(46) Francis, L. A.; Friedt, J.-M.; Zhou, C.; Bertrand, P. In Situ Evaluation of Density, Viscosity, and Thickness of Adsorbed Soft Layers by Combined Surface Acoustic Wave and Surface Plasmon Resonance. Anal. Chem. 2006, 78, 4200-4209.

(47) ProtParam Tool. http://web.expasy.org/protparam/ (accessed 16.08.2016).

(48) Volden, S.; Ese, M.-H. G.; Zhu, K.; Yasuda, M.; Nyström, B.; Glomm, W. R. Interactions Between Bovine Serum Albumin and Langmuir Films Composed of Charged and Uncharged poly $(\mathrm{N}$ isopropylacrylamide) Block Copolymers. Colloids Surf., B 2012, 98, $50-57$.

(49) Jourdain, N.; Carlón, R. P.; Reymond, J.-L. A Stereoselective Fluorogenic Assay for Aldolases: Detection of an Anti-Selective Aldolase Catalytic Antibody. Tetrahedron Lett. 1998, 39, 9415-9418. 